\title{
Determinants of Pastoralists Participation in Alternative Livelihoods: The Case of Amibara Woreda of Afar Region
}

\author{
Daniel Temesgen Gelan
}

\section{Introduction}

Afar Regional State is the fourth largest region $(99,646.54 \mathrm{~km} 2$ area) in Ethiopia, located in the northeastern part of the country. It shares boundaries with Tigray, Amhara, Oromia, and Ethio-Somali Regions of Ethiopia and also borders Djibouti and Eritrea (Afar Regional Atlas. 2014). Most of Afar Region has a harsh and dry landscape largely covered by desert scrubland. The entire region of Afar is classified under Pastoral and Agro-pastoralist production system. About $7.0 \%$ of the total area of the region is suitable for crop production; and $22.4 \%$ of the total area of the region could be developed for agricultural activity Afar land use policy 2008. The Afar economy is poorly diversified and not well integrated with the market. Afar pastoralists have witnessed the growing concern over extreme vulnerability and declining change in the traditional livelihood system (Tufts 2019). This is mainly due to multifaceted driving forces of change such as declining access to traditional land, demographic and policy changes, extreme climate events, market and other drivers. Among others, climate change posed a huge challenge; the most noticed variables are distributions and inconstancy of rain fall (Shekuru et al., 2020), increased temperatures and recurrent prolonged droughts (Fekadu, 2015;). These aggravated stock loss and impoverishment, food insecurity and conflict. The Afars are highly pastoralists and have access to few alternative economic activities, although rangeland resources contribute to the traditional activities in the past to support the household during crises. However, it has been observed that pastoralists are increasingly participating in alternative livelihoods to adapt to the changes. Dependence on alternative livelihoods has shown growing trends (Tufts 2019) and while livestock ownership often concentrated among wealthier households (Catley 2017). The Alternative livelihood included in this study are activities which are relatively in safe working environment, and takes place without harmful social or environmental consequences and include certain types of business development for those with access to capital or credit and related employment (Little 2016). The rising concern over food and livelihood security in the Afar region, government and development partners are promoting alternative livelihoods. The government Pastoral Development Policy 2018 is aimed at enhancing alternative livelihood as one of the paths for pastoralist development. Further, although a number studies were done in different corner on the alternative livelihood in pastoral areas. Few literatures are available on determinates of participation in alternative livelihoods; and, few information is available and no works had been done so far at the study area. Moreover, by examining the participation of pastoralist in alternative livelihood provide clear information on improving the enabling environment to alternative livelihood development through improvement skill training finance, business and entrepreneurship and technical support. Due to the above-mentioned facts, this study focused on assessing determinants of participation in alternative livelihood and pastoralists' perception towards alternative livelihoods. The objective of this paper is to examine the determinants of participating in to alternative livelihoods and analyzing the perception of pastoralist on alternative livelihoods.

DOI: $10.7176 /$ JPID/61-01

Publication date: January $31^{\text {st }} 2022$

\section{Methodology \\ Study area}

Amibara District is Part of the Administrative Zone 3 in Afar region bordered on the south by Awash Fentale District on the west by the Awash River which separates it from Dulecha on the northwest by the Administrative Zone 5, on the north by Gewane on the east by the Somali region and on the southeast by Oromia region. The community in Amibara District is where the biggest existing opportunities for alternative livelihood activities include commercial farms. Other opportunities are at the big construction companies. Other sources of employment are in basic service infrastructure such as telecommunication and electricity supply, schools and health institutions, and irrigation canals.

\section{Sampling design and sample size}

This study employed a multi-stage, stratified and random sampling technique. In the first stage, Amebara district of Zone 3 was selected purposely from the districts based on its access to alternative livelihoods. In the second stage, three Kebeles were selected randomly with the assumption that the all kebeles have similarity in the variable under consideration. In the third stage, sample was drawn from the two populations' stratum, participants and nonparticipants in Alternative livelihoods. Total sample size 100 was determined using Yamane (1967) formula with $\pm 5 \%$ precision level and $95 \%$ confidence interval. The total sample size was distributed to each sample kebele based on the proportional to sample size; finally Simple random sampling was used to select the study participants. 


\section{Data sources and data collection methods}

This study employed both qualitative and quantitative data collection methods. The qualitative data at community level were collected through focus group discussions, key informant interviews, and observations. The focus group discussions for this study were held with separate groups of elders, youth and women in each Kebele comprising 6-10 individuals per group. The sessions were moderated by the researcher using a checklist including climate change parameters in the area. Similarly, key informant interviews were held with knowledgeable people from the community. The data at the household level were collected through a household survey using structured questionnaires. Those were initially pretested to check their validity and appropriateness. Enumerators were enumerators were hired for data collection In addition; each of them is fluent speakers of the local language Afar Language.

\section{Data Analysis}

The data were analyzed using descriptive statistics specifically, means, percentages, frequencies distribution, standard deviation,; inferential statistics such as $t$ and Chi-square tests were used to find mean difference between participant and non-participants and determine statistically significance. In addition logistic regression analysis was employed to identify the determinants of in household participation in Alternative Livelihood. For this analysis, both SPSS and STATA version 20 were used. The qualitative data collected using key informant interviews, field observation, focus group discussion and oral histories were analyzed using narrative explanation and argument.

\section{Result and discussion}

\section{Socioeconomic characteristics}

The socio economic characteristic of the surveyed household is summarized in Table 1. It shows that among the presented features; farm experience, education level, total livestock unit, frequency of extension contact, distance from market, total annual income and non-farm income shows significant difference for participants and nonparticipants. The average farming experience of the participants is 7.66 and it is 10.13 for non- participants. The test statistical analysis revealed that there is significant difference in farming experience between participants and non-participants at probability level of less than $1 \%$. Income from non-farm activities is also significant at probability less than $1 \%$, with the mean annual income of 25,747.9 ETB, for participants and 2,308.7 ETB for non- participant. The result revealed that there is significant difference between participants and non- participants at less than $10 \%$ probability level in education level, TLU, and frequency of extension contact per month of user. Table 1. Summary statistics and distribution of continues variables

\begin{tabular}{|c|c|c|c|c|c|c|c|c|}
\hline \multirow[b]{2}{*}{ Variables } & \multicolumn{2}{|c|}{ Partic Ipant } & \multicolumn{2}{|c|}{ Non-par ticipant } & \multicolumn{2}{|c|}{ TcTal } & \multirow[t]{2}{*}{$\mathrm{T}$} & \multirow[t]{2}{*}{ P-value } \\
\hline & Mean & $\mathrm{SD}$ & Mean & $\mathrm{SD}$ & Mean & $\mathrm{SD}$ & & \\
\hline Age & 30.98 & 10.2 & 35.43 & 9.24 & 35.70 & 9.74 & -0.34 & 0.73 \\
\hline Farming experience & 7.66 & 4.82 & 10.13 & 5.45 & 8.90 & 5.27 & 2.88 & $0.004 * *$ \\
\hline Edu. Level & 1 & 2.83 & 1.01 & 2.13 & 1.35 & 2.52 & 1.62 & $0.10 *$ \\
\hline Family size & 6.05 & 3.01 & 6.05 & 3.02 & 6.05 & 3.01 & 0.00 & 1.00 \\
\hline Dependency ratio & 2.03 & .98 & 1.28 & .95 & 1.16 & .97 & 1.54 & 0.12 \\
\hline TLU & 18.28 & 17.5 & 10.40 & 18.01 & 12.84 & 17.8 & 1.64 & $0.10^{*}$ \\
\hline Farm size & 1.00 & 0.50 & .94 & .41 & .97 & .46 & .74 & 0.46 \\
\hline Ext. freq.in Month & 1.09 & 1.97 & 1.61 & 1.70 & 1.88 & 1.86 & -1.75 & $0.08 *$ \\
\hline Annual Income & 10666.8 & 13792.4 & 7173.4 & 11127.7 & 7920.1 & 12609.6 & -1.67 & $0.09 *$ \\
\hline Non-farm Income & $25,747.9$ & $30,388.8$ & 2308 & $1,067.7$ & $11,628.8$ & $24,470.6$ & -4.80 & $0.00 * *$ \\
\hline Dist. to district & 11.71 & 11.39 & 24.1 & 11.31 & 23.94 & 11.31 & 0.23 & 0.81 \\
\hline
\end{tabular}

\section{Econometrics Analysis}

AGE is significant at $\mathrm{p}<0.01$ level and related to pastoralists desire to participate in alternative livelihoods negatively. The odds ratio of 1.10 indicates that other factors constant, as the age increases by one year the likelihoods of participation in alternative livelihoods as a source of income decrease by a factor of 1.1. it is probably due to that older household heads participate less in alternative livelihoods, thus, older pastoralists are expected to be less active; and it is also related with resource endowment (livestock) than the youngsters. From FGD the youngest have been exposed to numerous new opportunities not experienced by the older generations, such as higher education, use of technology.

SEX The model output also indicated that it is significant $(p<0.05)$ and related to participation in alternative livelihoods positively. Other factors constant, the odds of 2.73 indicated that being female increases participation in alternative livelihoods by odd factor of 4.73. According to FGD result the changes from traditional pastoral production has impacted the roles men and women play at household level. With impoverished pastoral households women are now required to contribute financially to the subsistence needs of their families. The new role of women 
in the household has exposed women to alternative livelihoods activities to support the household needs.

Education: The model output however, indicate that Education level positively affected participation in alternative livelihoods at $\mathrm{p}<0.05$ level. The odd ratio of 0.818 indicated that other factors constant, participation in alternative livelihoods increased by odd factor of 0.818 with a unit increase in Education level. The probable reason educated pastoralists are more exposed to information which enables them to see opportunity to participate in alternative livelihoods. FGD result indicated that Education and subsequent employment was the most common desire of the educated youth. The majority of households who owned larger numbers of livestock did not desire education for all of their children. See quotes below from community members.

Non pastoral experience: The model output however, indicate that exposure to Non pastoral experiences positively affected participation in alternative livelihoods at $\mathrm{p}<0.01$ level. The odd ratio of 0.83 indicated that other factors constant, participation in alternative livelihoods increased by odd factor of 0.83 with a unit increase in exposure to Non-pastoral experiences. The probable reason is that the pastoralists with more exposure to Nonpastoral experiences are interested in alternative livelihoods due to accumulated experience and skill.

Annual income: The analysis result revealed that annual income affects participation in alternative livelihoods positively at $\mathrm{p}<0.01$ level. The odd ratio of 2.11 revealed that an increase in one unit of income increases participation in alternative livelihoods by the odds of 2.11 units. The possible explanation is that those household who had sufficient gain income: are more likely participate alternative livelihoods than those who did not gained enough income.

Distance to the district market: The distance of respondents to district market, affect participation in alternative livelihoods negatively. The result is significant at $\mathrm{p}<0.01$ probability level. Other factors constant, participation in alternative livelihoods increases by odd factor of 0.9 units with a unit kilometer decrease in distance to district market. The probably reason is that participation in alternative livelihoods is related to the opportunities created with decrease in distance to market and urban centers such as employment, labour, and production of high value horticultural crops.

Total livestock unit: It was significantly affected participation. Assuming other factors constant, as the number of livestock owned decreases by one TLU, participation in alternative livelihoods decrease by the odds of 0.97 . The result is statistically significant at $\mathrm{p}<0.05$ level. This is probably because pastoralists with lower TLU are tend to participate to alternative livelihoods to earn additional income to sustain their livelihoods than those with higher TLU which mainly earn from livestock. According to FGD results the pathway into non-pastoral alternative livelihoods by pastoral communities is often the result of a decline in their livestock holdings.

Input use: The use of input had determined participation in alternative livelihoods positively at $1 \%$ probability level. Citrus paribus, being a user of an input increases participation in alternative livelihood by odd factor of 17.98 units. The probable reason is that better productivity through input use on irrigated farming to go for participation as alternative livelihoods. This suggests that those who are better off can afford to buy fertilizer/ HYVs and those who are poor may not.

Cooperative participation: This variable is found to be significant at $\mathrm{p}<0.05$ level to positively determine participation in alternative livelihoods. Assuming other factors constant, being a member of cooperative organization increases participation by odd factor of 4.42. Further, FGD result indicated that pastoralists participate in cooperative and local organization for self-help, accessing input, alternative livelihoods management and maintenance, and marketing.

Perceptions on Alternative livelihood: This variable is found to be significant at $p<0.05$ level to positively determine participation in alternative livelihoods. Assuming other factors constant, positive attitude to alternative livelihood increases participation by odd factor of 4.42 . 
Table 2. Logit estimate of determinants of participation in alternative livelihoods

\begin{tabular}{|c|c|c|c|c|c|}
\hline Variables & Coefficient & Standard error & Odds ratio & $\mathrm{Z}$ & $\mathrm{P}>|\mathrm{z}|$ \\
\hline Constant & -9.04 & 2.65 & 0.00011 & -3.41 & $0.001 * * *$ \\
\hline Age & -0.102 & 0.042 & 1.108 & -2.48 & $0.01 * *$ \\
\hline Sex & 1.55 & 0.68 & 2.73 & 2.28 & $0.02 * *$ \\
\hline Education level & -0.200 & 0.15 & 0.818 & -1.33 & $0.184 * *$ \\
\hline Non pastoral experience & 0.184 & 0.07 & 0.832 & -2.62 & $0.009 * * *$ \\
\hline Family size & -0.084 & 0.132 & 0.919 & -0.63 & 0.525 \\
\hline Dependency ratio & -0.439 & 0.38 & 0.644 & -1.14 & 0.252 \\
\hline Distance to District market & -0.100 & 0.035 & 0.904 & -2.81 & $0.005 * * *$ \\
\hline Total livestock unit & -0.023 & 0.014 & 0.971 & -2.17 & $0.030 * *$ \\
\hline Total land & -0.58 & 0.73 & 0.559 & -0.80 & 0.426 \\
\hline Herd diversification & 1.194 & 1. 017 & 3.300 & 1. 11 & 0.268 \\
\hline Input access & 2.88 & 0.710 & 17.98 & 4.07 & $0.000 * * *$ \\
\hline Off farm income & 1.69 & 2.29 & 5.421 & 0.74 & 0.460 \\
\hline Non-farm income & 0.45 & 0.967 & 1.56 & 0.46 & 0.65 \\
\hline Credit participation & 0.30 & 0.86 & 1.35 & 0.36 & 0.721 \\
\hline Cooperative organization & 1.480 & 0.66 & 4.42 & 2.22 & $0.026 * *$ \\
\hline Extension frequency & 0.85 & 0.176 & 1.20 & 1.05 & 0.29 \\
\hline Access to irrigation & 1.480 & 0.66 & 4.42 & 2.22 & $0.026 * *$ \\
\hline $\begin{array}{l}\text { perception to alternative } \\
\text { livelihood }\end{array}$ & 0.102 & 0.420 & .108 & 1.48 & $0.01 * *$ \\
\hline
\end{tabular}

\author{
Number of Obs. $=124$ \\ LR Chi2 (17) $=83.18$ \\ Prob $>$ Chi2 $=0.0000$ \\ Pseudo R2 $=0.4898$
}

Log Likelihood $=-43.325574$

Source: model output. *** Significant at 1\%, ** significant at $5 \%$ probability level

\title{
Pastoralists' perception on the effect of Alternative livelihood participation
}

Respondents were asked about their perception on the effect of Alternative livelihood participation using five point Likert-type scale, i.e. 5= very high, $4=$ high, $3=$ medium, $2=$ low and $1=$ very low. In addition, the mean perception of respondents on the effects Alternative livelihood participation were categorized as 1.00-1.80 very low, 1.812.60 low, 2.61-3.40 medium, 3.41-4.20 high, 4.21-5.00 very high using the total mean score with equal interval of 0.8 unit.

Accordingly, the frequency distribution and percentage response of the indicated that $51.39 \%$ respondents perceived that effect of Alternative livelihood participation has strong effect on the productivity livestock. It was also reported that $57 \%$ and $27 \%$ of respondents perceived that Alternative livelihood participation has both strong and very strong impact on enhancing household income. With regard to enhancing food security $45.00 \%$ and $22 \%$ of respondents had medium and strong perceived that Alternative livelihood participation had effect. Majority $39 \%$ and $28 \%$ of the respondent's had medium and strong perception on the effect of Alternative livelihood participation in reducing vulnerability. While $34 \%$ and $43 \%$ of the respondents had strong and very strong perception on the effect of alternative livelihood participation on education respectively. However, the respondents were concern on the effect of participation in alternative livelihood on changing the customs and tradition. 
Table 3. Distribution of pastoralists perception towards effect on the alternative livelihood participation

\begin{tabular}{|c|c|c|c|c|c|c|c|c|c|c|c|c|c|}
\hline \multirow[t]{2}{*}{ Indicators } & \multicolumn{2}{|c|}{$\begin{array}{l}\text { Very } \\
\text { poor }\end{array}$} & \multicolumn{2}{|c|}{ Poor } & \multicolumn{2}{|c|}{ Medium } & \multicolumn{2}{|c|}{ Strong } & \multicolumn{2}{|c|}{$\begin{array}{l}\text { Very } \\
\text { strong }\end{array}$} & \multirow[t]{2}{*}{$\begin{array}{l}\text { mean } \\
\text { score }\end{array}$} & \multirow[t]{2}{*}{$\chi^{2}$} & \multirow[t]{2}{*}{$\begin{array}{r}\text { p- } \\
\text { value }\end{array}$} \\
\hline & $\mathrm{n}$ & $\%$ & $\mathrm{~N}$ & $\%$ & $\mathrm{~N}$ & $\%$ & $\mathrm{n}$ & $\%$ & $\mathrm{~N}$ & $\%$ & & & \\
\hline Effect on income & - & - & - & - & 16 & $16 \%$ & 57 & $57 \%$ & 27 & $27 \%$ & 4.21 & 15.25 & $.000 * *$ \\
\hline Effect on & & & & & & & & & & & & & \\
\hline $\begin{array}{l}\text { livestock } \\
\text { productivity }\end{array}$ & 9 & 9 & $14 \%$ & $14 \%$ & 44 & $44 \%$ & 28 & $28 \%$ & 5 & $5 \%$ & 3.00 & 16.19 & $.003 * *$ \\
\hline $\begin{array}{l}\text { Effect on food } \\
\text { security }\end{array}$ & 5 & $5 \%$ & 12 & $12 \%$ & 45 & $45 \%$ & 22 & $22 \%$ & 16 & $16 \%$ & 3.31 & 37.02 & $.000 * *$ \\
\hline $\begin{array}{l}\text { Effect } \\
\text { reducing } \\
\text { vulnerability }\end{array}$ & 7 & $7 \%$ & 14 & $14 \%$ & 39 & $39 \%$ & 28 & $28 \%$ & 12 & $12 \%$ & 3.13 & 12.44 & $.014^{*}$ \\
\hline $\begin{array}{l}\text { Effect on } \\
\text { Cultural custom }\end{array}$ & 11 & $11 \%$ & 9 & $9 \%$ & 25 & $25 \%$ & 35 & $35 \%$ & 12 & $12 \%$ & 3.17 & 13.29 & $0.01 *$ \\
\hline $\begin{array}{l}\text { Effect } \\
\text { education }\end{array}$ & 1 & $1 \%$ & 6 & $6 \%$ & 18 & $18 \%$ & 32 & $32 \%$ & 43 & $43 \%$ & 4.11 & 46.75 & $.000 * *$ \\
\hline
\end{tabular}

\section{Conclusion}

The study indicated that majority of pastoral community has perception that participating in alternative livelihoods has a positive effect on enhancing income, reduced vulnerability, and increased livestock productivity. The alternative livelihoods are new to the social system therefore requires new assets, such as skills, knowledge, attitude change. Age and sex are determinants to participating in alternative livelihoods implying to focus on youth and women empowerment in promoting alternative livelihood. The result indicated that education is determinant variable in participating in alternative livelihoods. Education is a powerful tool in promotes access to alternative livelihoods, either in urban or rural areas, at the same time female education encourages gender equality and is also directly linked to decreased fertility rates, particularly relevant in a community in which population growth is one of the biggest challenges. Furthermore, education can equip pastoralists with the skills and language and grant them access to decision making positions. Key areas of need for promoting and strengthening alternative livelihoods include: more appropriate education; vocational and skills training; and mechanisms for providing credit, stimulating savings and allowing investment. The entry points for income generation, innovative alternatives and production of commodities or services are also not in place.

\section{References}

Abebe, D., Little, P. D., Mahmoud, H. A., Stites, E., \& Bushby, K. (2016). Resilience and Risk in Pastoralist Areas: Recent Trends in Diversified and Alternative Livelihoods. USAID East Africa Resilience Learning Project Report

Afar Atlas. (2014). Regional atlas of Afar. Region Bureau of Finance and Economic Development, Semera Afar National Regional State Rural Land Use and Administration Policy (2008) Semera

Catley 2017. Pathways to Resilience in Pastoralist Areas: A Synthesis of Research in the Horn of Africa. Boston: Feinstein International Center, Tufts University,

Catley, A., and Y. Aklilu. 2012. Moving up or moving out? Commercialization, growth and destitution in pastoralist areas. In: A. Catley, J. Lind, and I. Scoones (eds.) Pastoralism and development in Africa. Dynamic Change at the Margins. Routledge, New York and Oxford

D.W. Pujiriyani, E. Soetarto, D.A. Santosa, et al.Rural hierarchy of prosperity: livelihood diversification and its implications on rurality Russ. J. Agric. Soc. Econ. Sci., 4 (88) (2019

FAO and Tufts University. (2019). Examining Alternative Livelihoods for Improved Resilience and Transformation in Afar. FAO: Addis Ababa, Ethiopia.

Fekadu K (2015) Ethiopian Seasonal Rainfall Variability and Prediction Using Canonical Correlation Analysis (CCA). Earth Sci 4(3):112-119. https ://doi.org/10.11648 /j.earth .20150 403.14

Helland, J. 2015. Afar resilience study. Feinstein International Center, Friedman School of Nutrition Science and Policy at Tufts University and Afar Region Disaster Prevention, Preparedness and Food Security Coordination Office, Afar Regional State, Ethiopia.

Inkermann, H. 2015. Diversification of livelihood strategies and the transformation of pastoralist life among Afar women in Baadu - Ethiopia. Occasional papers of the Centre for Development Geography, No. 04

Little 2016. Livelihoods Diversification Analysis (Lda) Literature Review

Little, P. D., K. Smith, B. A. Cellarius, D. L. Coppock, and C. B. Barrett 2001. Avoiding disaster: Diversifi cation and risk management among East African herders. Dev. Change 32

Scoones, I. \& Adwera, A. 2009. Pastoral innovation systems: Perspective from Ethiopia and Kenya. Future 
Agricultural Consortium, IDS, Brighton, UK.

Shekuru, A. H., Berlie, A. B., \& Bizuneh, Y. K. (2020). Variability and trends of temperature and rainfall over three agro ecological zones in North Shewa, central Ethiopia. 